\title{
The Need for a New Curriculum and a New Counselor in Nigeria.
}

\author{
Anselm Uchenna Anibueze $\mathrm{PhD}$ \\ General Studies Unit, Federal University Oye- Ekiti ,Ekiti State, Nigeria
}

\begin{abstract}
This paper studied the possibility of making a new counselor in Nigeria. The study discovered among other things that a new curriculum has to come on board to train counselors, that the new counselor has to be global competent, holistic, $21^{\text {st }}$ century active, online counseling competent, entrepreneurial, professional, dynamic, progressive etcetera. The paper noted the dare need for counselors in Nigeria to adopt counseling that can reach the unreached, especially; HIV/AIDS related cases, prisoners, drug users, teen pregnancies via tele or online counseling.
\end{abstract}

Keywords: counselor, curriculum, new, Nigeria

\section{Introduction}

For five decades now guidance/counseling has been a common practice in Nigeria, though much of its impact is felt in the school system. The Nigerian society has expected more than the present performance of guidance/counseling. It is an axiom that says "to whom much is given, much is expected". The society has expected that the spread of guidance/counseling would have reached the common man in the society today like; the street beggars, drug addicts, prisoners, cultists, corrupt officers, street children, drivers, etcetera. Today, it is like there is no counseling in Nigeria; counselors are not reaching out, counseling activities is centered in the school system where the ministry of Education is fortunately/unfortunately the major or sole shareholder/ employer. This paper addressed a search for; the new counselor, a new curriculum, that will prepare the counselor to reach out, to serve everybody, a counselor that will permeate the nook and crannies of the Nigerian society, a counselor that will be holistic, a counselor that is global competent, a counselor that is e-counseling based , a counselor that is entrepreneurial, a counselor that is Information and Communication Technology (ICT) complaint, a counselor that is professional minded, a counselor that is altruistic, a counselor that is functional, a counselor that is ne. In the course of this, these questions were asked; WHO will be the new counselor in Nigeria? WHAT will make a new counselor in Nigeria? HOW will a new counselor emerge in Nigeria? And WHY a new counselor in Nigeria

\section{Statement of Problem}

The problem of this study therefore, is that many Nigerian trained counselors are unemployed, some roam the streets looking for white-cola jobs or government employment and yet there are more jobs in the street unexplored; there are many street beggars, unemployed youths causing trouble, marijuana smokers, drug users/abusers, hopeless retired people, child hawkers, street-urchins, armed robbers, prisoners etc, these emotionally disturbed and maladaptive individuals patronize pastors, priest, soothsayers, traditional practitioners "dibbias" and "babalawos" who are regarded as quacks in counseling field. This paper wonders why these quacks, untrained and unprofessional counselors would thrive while the professional counselors are suffocating in the school system in abject poverty. One wonders whether counselors received any training in holistic, entrepreneurial, e-therapy. If they did, what hinders them from operating/practicing and addressing the ills in the society? This study wonders how new are counselors in Nigeria can be to exploit this virgin areas of employment, how abreast are these counselors in entrepreneurial education to harness the potential in counseling profession, how current are counselors in the new trends of counseling; online counseling, internet counseling, web discussions, e-conferencing etcetera. Again there is dearth of literature on how new or current, how prepared counselors are in Nigeria to face the emerging guidance and counseling challenges in the society, thus, the need for the study.

\section{How can a counselor be new in Nigeria?}

To become a new counselor in Nigeria, the counselor has to be current and move with the trend of societal needs, the counselor has to acquire some new skills especially some basic skills that enhance counseling services in the contemporary time. To be a new counselor is a kind of rebirth; it is adding some useful skills to enhance the already existing ones. It is a shift, a paradigm shift, a shift from the old way of counseling to a new approach. It is being holistic, that is reaching out to everybody, counseling everybody, counseling the 
maladjusted whether in the school or outside the school system, it is involving everybody; parent, teacher, the school environment, agencies, significant orders, it is being entrepreneurial etcetera.

\section{Why a counselor would be a new}

To meet the needs of people, to meet the millennium demands, to meet the $21^{\text {st }}$ century demands, to meet the Millennium Development Goal (MDG) demands, to be self reliant, to be a holistic counselor, to be relevant in the $21^{\text {st }}$ century as a counselor one need to be new.

\section{A Professional Counselor?}

A professional counselor is a person and his major role is to assist people, the society through the counseling relationship, he has to outline his own resources and his environmental opportunities in the process of self-understanding, planning, decision-making and coping with problems relative to the developmental needs and to educational and vocational activities of his client (Olayinka, 1993) "The professional goal of the counselor is to foster the psychological development of the individual".

A professional counselor is; a counselor who respects the dignity, integrity and promote the welfare of his clients at all time, a counselor who is co-operational and not coercive, a counselor who promotes the personal well-being and development of the individual, a counselor who respects the cultural values and practices that promotes the positive behaviors development and development of the individual., a counselor who help clients to create awareness of self, values, interests, capabilities, aptitudes, strengths and weaknesses., a counselor, who works to help individuals to adjust well, be self- reliant, and can take wise choices without elders', parents, or teachers support, a counselor who help individuals adjust satisfactorily to their society.

\section{VI. . A Holistic Counselor?}

A holistic counselor is one

Who knows a little of everything, and does much of a particular thing

Who does a little for everything,

Who counsels everybody,

To be a holistic counselor, one remembers that counseling is for everybody, this means that guidance and counseling is not for only the student, it is not only for the maladjusted but also for the adjusted. (Onuigbo 1997) stated that, guidance services serve more to all students not merely to those who are found to deviate in some ways. In addition guidance and counseling is required to serve the public not merely the student. Guidance and counseling should reach the sick, the healthy, the rich, the poor, civil servants in- lure of preparing for retirement, retirees in-lure of adjusting to retirement, the bereaved, the prostitutes, the HIV/AIDS patients, prisoners, drivers of all sort, industrial workers, street children, special people, aged people, drug addicts, cultist, physical, mental, emotional handicapped people etcetera. A new curriculum for a new counselor in Nigeria should embrace and contain these as mentioned above. This is to say that guidance and counseling is to serve the society and not only the school system as observed in Nigeria.

\section{Information and Communication Technology (ICT) Compliant}

The counselor who is ICT compliant is one who knows how to make use of the computer, who is computer literate, who can access the net, who counsels the client with computer assisted services, a computer which is connected with the international community, who is in the global village. The question is, how many of us counselors are ICT compliant, how many of us own a computer, how of us can afford to acquire a computer, how many counselors in Nigeria have counseling clinics/laboratories outside the school building and how many schools have a computer laboratory and how many of us know what is being ICT compliant. Being ICT compliant, is, the ability to employ computer services in the delivery of counseling services, duty or job. It involves online counseling, e-therapy e-conferencing etcetera.

\section{Online Counseling}

One of the emerging new curriculums in counseling and the world of work are computer assisted services. Online counseling is variously referred to as; internet counseling, e-counseling, e-mail counseling, etherapy, web counseling, e-psychotherapy, internet psychotherapy, or online counseling/psychotherapy (Heinlen, Welfel, Reynolds, Richmond, \& Rak, 2003; Patrick, 2006). The multiplicity of terms speaks to the lack of clarity about how to label a professional activity delivered through a medium that can be used in a variety of ways. As computer technology has become the "norm" in offices, homes, and as wireless transportable devices, the extension of the potential uses of internet capabilities has expanded at an astounding rate. Within counseling, however, the extension of counseling delivered through computer technology has had mixed results. The technology revolution has dramatically expanded the capacity for person-to-person communication than spans time zones, geographic location, convenience, and time gaps between sending and 
receiving messages. At the same time, the counseling professions have ventured into the computer mediated world of online counseling leveraging the potential to extend access to counseling services. Foundational to the traditional model of the counseling process, however, is the face to face encounter between client and counselor. How can this qualitative element of human interaction be duplicated in a virtual environment? While the real time personal meeting that has represented an unquestioned forum in which to conduct counseling has not been replaced by online counseling, issues have been identified that speak to controversies about the efficacy of online counseling as a helping process and legitimate form of providing mental health services. As online technologies have facilitated increased communication and work management, they simultaneously have led to a redefinition of counseling, and how counseling can be practiced, in ways not imagined a generation ago. To understand the appeal of online counseling, it is essential that counselors understand client characteristics of those who are most likely to use online counseling services; have a solid understanding of the appealing qualities of computer mediated counseling; be able to identify the core issues that must be carefully evaluated by counselors contemplating providing online counseling services; and finally, carefully consider the issues of access to online counseling by underserved cultural and ethnic populations.

\section{Nigeria and Internet Counseling}

If internet counseling does exist in Nigeria today, it does not exist within the purview of the counseling. Nigeria is worse because there are no infrastructures for such public consumption. There are no regular electricity, $90 \%$ of people are not computer literate, the literate ones does not have computer, there are very few ciber cafe and these ciber café does exist only in the cities. Counselors are yet illiterate in the use of computer and computer assisted counseling; internet counseling is not covered by the curriculum for counselors in training. We shall not fail to point out that counseling is yet school based. For over five decades counseling is not within the purview of the public consumption. There is no counseling services for the bereaved, the sick, retirees, HIV/AIDS patients, the prisoner, drivers and motor bike rider, prostitutes, street children, private counseling out fits. People resort to quack counseling like patronizing; priests, soothsayers, medicine men, pastors, magicians' significant persons etcetera. A new counselor with a new curriculum is needed to address these problem areas.

Internet counseling can be employed to assist; technology-assisted distant individuals, telephone-based individuals, telephone-based couples, telephone-based groups, e-mail based individuals, chat-based individuals, chat-based couples, chat-based groups, video-based individuals, video-based couples, and video-based groups. Telephone-Assisted Distance counseling for individuals, couples and groups involves the use of the telephone or the computer to enable counselors and clients to communicate at a distance when circumstances make this approach necessary or convenient. Tele-counseling involves synchronous distance interaction among counselors and clients using one-to-one or conferencing features of the telephone to communicate.

The telephone-based group counseling involves synchronous distance interaction among counselors and clients using what it heard via audio to communicate. This kind of counseling does not exist in Nigeria today, and there is need to establish it to reach certain unreachable people and those who do not want to disclose their identity.

Internet counseling involves a synchronous and synchronous distance interaction among counselors and clients using e-mail, chat and video conferencing features of the internet to communicate.

On the internet, most of the time it is adolescents who used the computer and they are usually very quick to open up and share their feelings. There are opportunities for helping people, especially teenagers who often feel trapped and very alone. For most of them the internet is sometimes literally their lifeline. They are used to chatting and e-mails often prefer this type of communication for instance a school made a statement that student e-emailed him and asked if they could e-mail each other about some problems she was having at home. But when he told her, he preferred that she come in and see him face to face, she stopped talking to him together. This kind of situation could be avoided if the internet was used as another counseling tool. Perhaps later the girl would have felt more comfortable talking to the counselor in person.

\section{Issues for E-Counseling}

In general it is going through a tough time issues like; spiritual issues, anxiety, anger, stress, depression, (negative experiences), self-esteem and self-image, dealing with a loss or struggling through a life transition, personal problems, self-improvement, self-help, relationship issues like conflict, rejection, improvement, breaking up recovery, sex matters, marriage and family issues private issues that usually induces fear and shyness,. Others that need serious internet counseling in Nigeria include; rape situation, HIV/AIDS, venereal diseases, domestic violent, career, and marriage partner etcetera. 


\section{Global competent}

To be global competent, a counselor need to fit in into the world market of work, such a counselor can compete with other counselors in the world without fear or favor, a counselor who is not Nigerian constrained, a Nigerian counselor who can go to USA, Britain, Ghana, South Africa, Germany, Canada, Japan, South Africa, India, Egypt etcetera and still fit in as a competent counselor without antagonism or discrimination. Other Nigerian professional like; medicine, engineering, academia fly very high in Diaspora. To be a new counselor in Nigeria with a new curriculum, the counselor must be marketable worldwide not only in Nigeria.

\section{21st century competent}

To be $21^{\text {st }}$ century competent, the counselor has to be current, has to be competent to capture the events of today. The world of today is bedeviled by crisis of social, psychological, environmental and personal vices that demand a lot of attention. This goes to suggest that there is a new demand for a new counselor with a new curriculum to tackle the new problems. A new counselor has to be abreast with these problems with new approaches to solving them. The new counselor of the $21^{\text {st }}$ century order should be entrepreneurial, e-counseling based, in fact versatile

\section{The Counselor and entrepreneur}

The concept of entrepreneur dates back to early period. Entrepreneur is a French word, meaning gobetween or between- taker. In the early period entrepreneur meant an individual who takes risks and starts something new. Marco Polo was used to exemplify the early entrepreneurs, he was giving money to merchants who go to procure goods/items and sell with profit where Marco Polo will take $75 \%$ of the profit and the merchant 25\% Marco Polo is the risk bearer in the business.

In $17^{\text {th }}$ century entrepreneur was understood as risk taking in business adventure. Richard Cantillon one of the first theorists viewed the entrepreneur as a risk taker, observing that merchants, farmers, craftsmen, and other sole proprietors "buy at a certain price and sell at an uncertain price, therefore operating at a risk"(Hisrich, Peters, Shepherd 2008 ). Another good example of entrepreneur in the $17^{\text {th }}$ century is that the entrepreneur is a person who entered into a contractual arrangement with the government to perform a service or to supply stipulated products. Since the contract price was fixed, any resulting profits or losses were the entrepreneur's

The $18^{\text {th }}$ century saw the entrepreneur not only as a risk taker but an innovator, an individual developing something. The entrepreneur shifted from capital provider, risk taker to innovator or initiator "an individual developing something unique". The $19^{\text {th }}$ and $20^{\text {th }}$ century understood entrepreneur in broad sense encompassing, newness, trying a new way of doing things, taking difficult task, conceptualizing, creating, reforming reorganizing and understanding and undertaking the forces at work in an environment. As put by Hisrich et al (2008), "the function of the entrepreneur is to reform or revolutionalize the pattern of production by exploiting an invention or, more generally, an untried technological method of producing a new commodity or producing an old one in a new way, opening a new source of supply of materials or a new outlet for products, by organizing a new industry".

Although each of these definitions views the entrepreneur from a slightly different perspective, they all contain similar notions, such as newness organizing, creating, wealth, and risk taking. Yet each definition is somewhat restrictive, since entrepreneurs are found in all professions - education, medicine, research, law, architecture, engineering, social work, distribution, and the government.

Summarily, in this write-up, we join Hisrich (2008) in his definition of entrepreneur as "the process of creating something new with value by devoting the necessary time and effort, assuming the accompanying financial, psychic, and social risks, and receiving the resulting rewards of monetary and personal satisfaction and independence. A new counselor in Nigeria need to employ the entrepreneurial initiative by creating job for himself and others". Entrepreneurship is a key driver of any economy, wealth and a majority of jobs are created by small business started by entrepreneurial minded individuals, many of whom go on to create big business. According to Fred (1993), Entrepreneurship is the launch and or growth of ventures through the use of innovative, risk assuring management". Entrepreneurship means the act of creating or growing a business through innovative and risk-assuming management.

People exposed to entrepreneurship frequently express that they have more opportunity to exercise creative freedoms, higher self esteems, and an overall greater sense of control over their own lives. Because of this many experienced business people, political leadership, economists and educators believed that fostering a robust entrepreneurial culture will maximize individual and collective economic and social success on a local, national and global scale. Therefore, entrepreneurship is NOT learned by reading a textbook and then taking a test to prove you are one. Entrepreneurs are not "born" they "become" through the experiences of their lives.

Entrepreneurs have a great diversity of personal characteristics, the common one is an individual willingness to take a calculated risk in return for profit. No educational degree is required to become an 
entrepreneur, it is helpful to have developed good support skills including; communications skills, interpersonal abilities, economic understanding, digital skills, marketing, management and financial skills.

\section{E-Energy}

The key in entrepreneurship is hard work, but also in a smart way. For one to be able to provide solutions to issues and for the successful completion of projects, a lot of both mental and physical energy is needed. So to sustain this energy, an individual need to stimulate his brain and his senses; of sight, hearing, touch, smell and taste so that they all stay alert in identifying what needs to be done in different situations of a particular environment.

\section{N- Need to achieve}

The entrepreneur must have the motivation to achieve success and accomplish all the activities he engages in. His attitudes and perceptiveness enable him to work towards acceptable results whenever he set out to do something. This approach enables him to work harder than the ordinary man or woman.

\section{T- Task Oriented}

For one to obtain satisfying rewards, tasks have to be well executed and completed on time. Efficiency, effectiveness and time management are important aspects that enable you to complete tasks. To focus on results help one to concentrate on whatever task he set out to do.

\section{E-Empathy}

The entrepreneur should mentally put himself in the position of the person or person's he intend to influence. He should be able to put himself into their shoes, so that he feels what they feel. So in business, he should be able to imagine how a potential customer would feel.

\section{R-Resourcefulness}

It is about providing leadership, guidance needed to realize the enterprise so the identification, mobilization and effective utilization of both the physical and the non-physical resources needed in undertaking a venture are very important in the enterprise process.

\section{P-Planning}

For one to see the total picture of the enterprise of why the organization is set up, what needs to be done, how it will be done, who will do it and when it will be done, so it is necessary to establish written plan. It is through planning that indicate on whether there will be profits or losses or losses will be made available.

\section{R-Risk taking}

Success begins with the decision to start moving in the right and desired direction. An entrepreneur is the only person that knows how to take calculated risk. He is a good risk bearer.

\section{I-Innovation}

The ability to apply new ideas that will enable you to undertake activities differently is another hallmark of an entrepreneur through individual, initiative, imagination, intuition and insight. The entrepreneur will be able to change things around or devise ways of doing things to accommodate whatever new situation that may arise. An entrepreneur may find himself in. an enterprising individual's place, great value on information and are always alert and constantly engaging in research.

\section{S-Skills}

An entrepreneur is one that has the ability or know-how that enables him to undertake and complete activities. He/she must have a certain amount of knowledge, attitudes and practical skills that can be useful when realizing an enterprise. So you should evaluate the talents and level of skills you have and how they can be harnessed to realized an enterprise.

\section{E-Endurance}

For one to set up enterprises there are many challenges to face, some are negative and discouraging. Patience, persistence and confidence are some of the attitude one will need to adopt to enable one to endure the physical and mental challenges that are inherent in an enterprise or an adventure, ( Hisrich 2008). How many counselors in Nigeria oblige to this? Most of the counselors are white cola job centered, most wait for government employment, and $98 \%$ of counselors employed are school based/centered, the rest are unemployed loafing about when there are needy clients in the street, quacks; medicine men, pastors, priests, born again 
pastors, overzealous religious leaders, soothsayers, imams, traditional medicine men/herbalists are the order of the day.

\section{Recommendations}

In the course of this study, the following recommendations were made;

1) A call for a review of the minimum standard of courses offered in guidance and counseling, to train counselors in the new counseling skills; to be entrepreneurial, e -counseling competent, online competent, professional, functional, holistic, dynamic and progressive.

2) Nigerian trained counselors should move out of the present state of training and acquire some basic entrepreneurial skills to augment the shortfall in the course content in Nigerian universities.

3) Policy makers, ministry of education, educational agencies, teachers/counselors, parents and other

Stakeholders in education sector should help in advertising counseling services to benefit all in the society.

4) Counselors in Nigeria should be encouraged and persuaded to go for retraining to include other method of counseling like internet counseling, telephone counseling, chart-counseling, to become more effective in counseling service delivery.

5) Counseling Association of Nigeria should organize workshops and training for her members on the latest form of counseling and be introduced to a new paradigm in counseling that can produce results fast and easier than before.

6)There is a need for counselors in Nigeria to adopt counseling that can reach the unreached and those who do not want to disclose their identity especially HIV/AIDS related counseling and teen pregnancies. 7) Government should create enabling environment for counselor to functions without interference and distractions from government authorities or agencies.

8) Counselors are advised to open up private clinics and laboratories to handle social problems that are not school based.

9) There is a need for a massive enlightenment to enlighten member of the public about the importance of counseling services in Nigeria.

10) Counselors should understand that only change is constant, that there is a need for paradigm shifts in counseling because it is obvious that the old method is not working.

\section{Conclusion}

A new counselor in Nigeria is one who has acquired new skills in counseling delivery. One who passed through a new curriculum that makes use of e-counseling, the type of counseling that reaches everybody, curriculum that is not centered in the school, and a curriculum that is holistic, all embracing? A counselor can be new in Nigeria by allowing the counselor to pass through a new curriculum that is current and can reach every segment of the society above the school system. Why a counselor needed to be new is highlighted in the study and a discovery showed that the old system does not work, it is no more current and cannot stand the test of $21^{\text {st }}$ century, it does not reach everybody, it is school centered, does not reach; the needy, special people, retiree, aged, prisoners, delinquents etcetera, therefore needing a change and a new approach.

THANK YOU.

\section{Reference}

[1]. Fred, R. O. (1993) in Kaufman, R and Zahn, O. (1998). Quality management plus: the continuous involvement of Education. Newburg park. CA: Corwin press.

[2]. Heinlen,Welfel,ReynoldsRichmond,\&Rak,(2003);Patrick,2006http/www.biblical.edu/images/conn 20Counseling. Retrieved August 12, 2010 at Web Site

[3]. Hisrich, Peters, Shepherd (2008) Entrepreneurship. Singapore; Mcgraw-hill companies Inc.

[4]. Olayinka, (1993) in Onuigbo A.U.(1997), Essentials of Guidance and Counseling. Nsukka, Nigeria: Chuka Educational Publishers.

[5]. Ricchard C. in Odimegwu, F.B.O (2005). Meeting the challenges of human capital development: the case for reforms in our educational policies and system. In University of Nigeria Nsukka $34^{\text {th }}$ Convocation. $31^{\text {st }}$ March 2005.

[6]. University of Nigeria Calendar Editorial Board. University of Nigeria, 2004- 2006 calendar, Enugu Rainbow Paper Mill LTDs- 